\title{
Observations of Earth-Ionosphere Cavity Resonances and Their Interpretation in Terms of a Two-Layer Iono- sphere Model
}

\author{
F. W. Chapman and D. Llanwyn Jones
}

Wheatstone Laboratory, University of London King's College, Strand, London, W.C.2., England

(Received June 23, 1964)

\begin{abstract}
The frequencies of the resonance modes of the earth-ionosphere cavity have been determined by means of a direct recording integrating spectrometer over a period of one year and diurnal and seasonal changes have been observed. The experimental data on the frequencies of the first few resonant modes are interpreted in terms of a model ionosphere consisting of two discrete homogeneous regions. A model which accounts for the observations is derived and the propagation constant of extremely low frequency electromagnetic waves, appropriate to worldwide propagation has been determined for the derived model. The results are compared with those obtained by other workers using a different approach.
\end{abstract}

List of Symbols

$A(f)$
$E_{r}$
$I(t)$
$P_{n}(\cos \theta)$
$S_{0}$
$a$
$c$
$f$
$f_{n}$
$f_{n}^{\prime}$
$h$
$j$
$l$
$m$

$m$

Source term $-\frac{l(t) l \eta}{8 \pi^{2} a^{2} \epsilon_{0} h}$ field equation

Radius of the earth in free space

Frequency $(\mathrm{c} / \mathrm{s})$ $c \sqrt{n(n+1)} / 2 \pi a$

$\sqrt{-1}$ model $-m q$ 3 ...

Stratification factor

$\sqrt{\omega_{r}^{\prime \prime} / \omega_{r}^{\prime}}$ waveguide mode $=\sqrt{\mu_{0} / \epsilon_{0}}$ model
Radial (vertical) component of electric

Lightning discharge current

Legendre polynomial of order $n$

Solution of zero order waveguide mode

Velocity of electromagnetic radiation

Eigen frequency of cavity resonator-

Observed (damped) eigen frequency

Altitude of lower region of model

Effective length of lightning discharge.

Ionospheric loss parameter of lower region of model $-c / h \sqrt{\omega_{r}^{\prime}}$

Effective loss parameter for two layer

Order of resonance mode $n=0,1,2$,

Thickness of lower region of model

Propagation constant of zero order

Permittivity of free space

Characteristic impedance of free space

Permeability of free space

Refractive index of lower region of

Conductivity of lower region of model

Conductivity of upper region of model $\omega$

$\omega_{r}^{\prime}$

$\omega_{r}^{\prime \prime}$

Angular frequency - $2 \pi f$

Conductivity parameter of lower region of model $-\omega_{r}^{\prime}=\sigma^{\prime} / \epsilon_{0}$

Conductivity parameter of upper region of model- $\omega_{r}^{\prime \prime}=\sigma^{\prime \prime} / \epsilon_{0}$

\section{Introduction}

The existence of natural resonances of the earthionosphere cavity was first predicted by Schumann $[1952 \mathrm{a}, \mathrm{b}]$ on the basis of a theoretical formulation of the electromagnetic field in the thin spherical shell bounded by the surface of the earth and the lower ionosphere. These may be described in terms of a standing wave pattern produced by the interference of direct and antipodal ELF (extremely low frequency) waves originating in worldwide lightning discharges. It is of interest to note that as long ago as 1893 the possibility of earth resonances was examined [Fitzgerald, 1893]. At that time the existence of the ionosphere had not been established, but the modification of the frequencies of the earth resonances by a conducting layer in the upper atmosphere was discussed and Sir Oliver Lodge made some unsuccessful attempts to detect the resonances.

Since the publication of Schumann's results, much experimental and theoretical work has been carried out in order to detect cavity resonances and account for the experimental observations. Schumann [1952a] had shown that the resonant frequencies of the earthionosphere cavity may be expressed as

$$
f_{n}=c \sqrt{n(n+1)} / 2 \pi a
$$

if both the earth and the ionosphere were regarded as perfect conductors. The resonant frequencies predicted by this law are $10.6,18.3,25.9,33.5 \mathrm{c} / \mathrm{s}$ for $n=1,2,3,4$.

König $[1954,1959]$ has claimed to verify the existence of such resonances experimentally by observing the waveform of atmospherics in a relatively narrow band channel. He reports the existence of transient 
quasi-sinusoidal disturbances with an apparent frequency of $9 \mathrm{c} / \mathrm{s}$. Polk and Fitchen $[1962,1964]$ have observed similar effects and obtained a good correlation between the observed disturbances and worldwide thunderstorm cavity. In order to establish the existence of the resonances on a statistical basis, however, it is necessary to examine the spectrum of ELF electromagnetic noise in the region 5 to 40 $\mathrm{c} / \mathrm{s}$, since it would be expected that this spectrum would contain maxima corresponding to the natural modes of oscillation of the cavity. The first statistical study of the ELF noise spectrum was that of Balser and Wagner [1960a], who initially detected small but nevertheless significant enhancements in the 50 to $100 \mathrm{c} / \mathrm{s}$ region and later, by means of a digital sampling technique and power spectrum analysis, demonstrated the existence of cavity resonances in the frequency band 5 to $50 \mathrm{c} / \mathrm{s}$ [Balser and Wagner, 1960b]. Other observers have since verified the existence of cavity resonances, generally by employing a sonometer or spectrometer provided with electronic facilities for integration of the noise spectrum [Fourier, 1960; Benoit and Houri, 1962; Lokken et al., 1961; Chapman and Jones, 1964a; Ryecroft and Wormell, 1964; Gendrin and Stefant, 1962a, b]. The extent of the data of Gorskii and Krotov [1961] is not clear, but it seems likely that a reported narrow band $9 \mathrm{c} / \mathrm{s}$ enhancement was only occasionally observed. On the other hand some observers of ELF noise phenomena have failed to detect cavity resonances, although their observations included the frequency range of this phenomenon [Aarons 1956, 1960a, 1960b; Large, 1958; Stefant, 1960; Haraldson, 1961]. Failure to detect cavity resonances may be ascribed to the experimental method employed.

Since the initial theoretical work of Schumann [1952a, b], the theory of the resonator phenomena has been extended to consideration of the effects of the finite conductivity of the ionosphere. Schumann [1957] has considered the sharply bounded homogeneous ionosphere model and shown that the effect of finite ionospheric conductivity is to lower the resonant frequencies of the cavity. Raemer [1961] has computed the ELF noise spectrum in terms of the homogeneous model, and Chapman and Jones (1964a] have discussed the interpretation of the resonator data on the basis of this model and derived effective ionospheric parameters. It has been shown [Galejs, 1961a] that, while the homogeneous model may be used in order to explain the observed frequencies of the resonances, it cannot at the same time explain the observed $Q$ factors. For this reason Galejs has considered an exponential model and shown that such a model can explain the $Q$ factors of the resonances and predict the frequencies to within $0.5 \mathrm{c} / \mathrm{s}$. The effects of the earth's magnetic field on the resonances have been considered by Madden et al. [1962], Galejs [1963], and Galejs and Row [1964], have determined the effect of positive ions and the earth's magnetic field and found that both factors influence ELF propagation to some extent. Most of the theoretical work discussed above requires a knowledge of the ionospheric electron and ion density profiles for the lower ionosphere. An exception is the work of Harris and Tanner [1962], who derived a value for the ELF propagation constant without reference to an ionspheric profile.

We have been concerned with the extension of the experimental values of the attenuation constant of long radio waves obtained by Chapman and Macario [1956] in the frequency range $100 \mathrm{c} / \mathrm{s}$ to $10 \mathrm{kc} / \mathrm{s}$ to lower frequencies. It was not possible to employ the method of Chapman and Macario at lower frequencies due to certain theoretical objections [Wait, 1960a]. Observations of the frequencies of the cavity resonances, however, enable an accurate value for propagation constant of ELF waves with frequencies of the order of $10 \mathrm{c} / \mathrm{s}$ to be determined though, due to the nature of the resonance phenomenon, only the average value of the propagation constant on a worldwide basis may be found by this method. In the theoretical work reported here, it is shown how the observations on cavity resonances may be interpreted in terms of a two-layer model ionosphere by deriving a two-layer profile which predicts the frequencies of the resonances to within a few tenths of a cycle and corresponding $Q$ factors which agree reasonably well with the experimental observations. An ionosphere profile that is effective in worldwide propagation is thus obtained, and the propagation constant appropriate to the profile is then determined. This process eliminates the necessity of 'averaging' day and night profiles found in some other methods of interpretation.

\section{Experimental Study}

\subsection{Instrumentation}

The instrumentation has been described by Chapman and Jones [1964a]. Briefly the system consists of a vertical rod antenna (which responds to the vertical component of the electric field) feeding into an amplifier system via a matching impedance transformer. The total gain available is $100 \mathrm{~dB}$ and may be varied by means of an attenuator. The amplified signal is fed into a constant $Q$, sweptfrequency spectrometer operating in the range 4 to $40 \mathrm{c} / \mathrm{s}$. The frequency of operation is controlled by a synchronous motor and is swept through the decade of the spectrum in a period of one hour. The output from the spectrometer is integrated by means of an RC circuit and passed via a d-c power amplifier to a pen recorder, thus producing a record of the amplitude-frequency spectrum of the received noise signal.

\subsection{Experimental Results}

The spectrometer system has been employed in studies of the ELF noise spectrum during the period June 1961 to August 1962. In all some 5000 spectra were obtained during the recording period. Initially some spurious effects were observed primarily due to local sources of interference and due to wind and rain [Jones, 1963]. Local interference limited the amount of useful data which could be collected, but 
earth-ionosphere cavity resonance effects were immediately observed in the spectrum. The results reported below refer to measurements on about 500 spectra in which cavity resonances were clearly defined. Attention has mainly been confined to the determination of the resonator mode frequencies, since a preliminary theoretical study has shown that the mode frequencies rather than their amplitude were the most significant for determining the propagation constant. Generally speaking, however, it is of interest to note that the amplitude of the first order mode was found to be approximately $150 \mu \mathrm{v}$ sec $\mathrm{m}^{-1}$, this figure being determined by comparison with the amplitude of the $16 \mathrm{kc} / \mathrm{s}$ transmission of G.B.R., the field strength of which was known. The results obtained by analysing the recorded spectra are given in table 1 in which the mean monthly frequencies of the resonator modes are tabulated.

TABLE 1. Number of observations, N, and mean monthly frequencies, $\overline{\mathrm{f}}_{\mathrm{n}}$, of cavity resonator modes

\begin{tabular}{|c|c|c|c|c|c|c|}
\hline \multicolumn{2}{|l|}{ Mode order } & 1 & 2 & 3 & 4 & 5 \\
\hline July $1961 \ldots$ & $\mathrm{N}$ & 87 & 31 & 26 & 61 & 16 \\
\hline August_.. & $\begin{array}{l}\bar{f}_{\mathrm{n}} \\
N\end{array}$ & $\begin{array}{c}8.3 \\
39\end{array}$ & $\begin{array}{l}13.2 \\
20\end{array}$ & $\begin{array}{l}20.1 \\
26\end{array}$ & $\begin{array}{l}25.9 \\
17\end{array}$ & $\begin{array}{c}33.3 \\
3\end{array}$ \\
\hline September. . & $\begin{array}{l}\bar{f}_{\mathrm{n}} \\
\mathrm{N}\end{array}$ & $\begin{array}{l}8.1 \\
35\end{array}$ & $\begin{array}{c}14.2 \\
9\end{array}$ & $\begin{array}{c}20.2 \\
6\end{array}$ & $\begin{array}{c}26.9 \\
3\end{array}$ & $\begin{array}{c}33.0 \\
0\end{array}$ \\
\hline November & $\begin{array}{l}\bar{f}_{\mathrm{n}} \\
\underline{N}\end{array}$ & $\begin{array}{l}8.89 \\
6\end{array}$ & $\begin{array}{l}13.1 \\
11\end{array}$ & $\begin{array}{c}20.0 \\
4\end{array}$ & $\begin{array}{c}26.3 \\
4\end{array}$ & 3 \\
\hline December. & $\begin{array}{l}\bar{f}_{\mathrm{n}} \\
\mathrm{N}\end{array}$ & $1_{13}^{8.15}$ & $\begin{array}{l}14.4 \\
13\end{array}$ & $\begin{array}{c}20.0 \\
4\end{array}$ & $\begin{array}{c}25.8 \\
3\end{array}$ & $\begin{array}{c}33.0 \\
1\end{array}$ \\
\hline Jan. 1962 & $\begin{array}{l}\bar{f}_{n} \\
N\end{array}$ & $\begin{array}{l}7.95 \\
9\end{array}$ & ${ }_{2}^{14.15}$ & $\begin{array}{c}20.5 \\
3\end{array}$ & $\begin{array}{c}26.3 \\
2\end{array}$ & $\begin{array}{c}32.0 \\
1\end{array}$ \\
\hline February & $\begin{array}{l}\bar{f}_{n} \\
N\end{array}$ & $\begin{array}{l}8.26 \\
37\end{array}$ & $\begin{array}{l}14.1 \\
17\end{array}$ & $\begin{array}{c}20.7 \\
9\end{array}$ & $\begin{array}{c}26.5 \\
6\end{array}$ & $\begin{array}{c}32.0 \\
0\end{array}$ \\
\hline March _- & $\begin{array}{l}\bar{f}_{\mathrm{n}} \\
\mathrm{N}\end{array}$ & $\begin{array}{c}8.03 \\
66\end{array}$ & $\begin{array}{l}14.2 \\
22\end{array}$ & $\begin{array}{l}20.2 \\
10\end{array}$ & $\begin{array}{c}25.8 \\
5\end{array}$ & 1 \\
\hline April__- & $\begin{array}{l}\bar{f}_{\mathrm{n}} \\
\mathrm{N}\end{array}$ & $\begin{array}{l}7.97 \\
26\end{array}$ & $\begin{array}{l}14.3 \\
17\end{array}$ & $\begin{array}{l}20.4 \\
11\end{array}$ & $\begin{array}{c}26.2 \\
8\end{array}$ & $\begin{array}{c}33.0 \\
3\end{array}$ \\
\hline May_- & $\begin{array}{l}\bar{f}_{\mathrm{n}} \\
\underline{N}\end{array}$ & 84.94 & $\begin{array}{l}13.9 \\
56\end{array}$ & $\begin{array}{l}20.9 \\
38\end{array}$ & $\begin{array}{l}26.2 \\
26\end{array}$ & $\begin{array}{l}32.3 \\
18\end{array}$ \\
\hline June_. & $\begin{array}{l}\bar{f}_{n} \\
N\end{array}$ & $\begin{array}{l}8.01 \\
108\end{array}$ & $\begin{array}{l}14.2 \\
99\end{array}$ & $\begin{array}{l}20.2 \\
65\end{array}$ & $\begin{array}{l}26.0 \\
48\end{array}$ & $\begin{array}{l}33.1 \\
48\end{array}$ \\
\hline July _. & $\begin{array}{l}\bar{f}_{n} \\
N\end{array}$ & $\begin{array}{l}7.83 \\
5\end{array}$ & $\begin{array}{c}14.1 \\
3\end{array}$ & $\begin{array}{c}20.1 \\
2\end{array}$ & $\begin{array}{c}25.8 \\
1\end{array}$ & $\begin{array}{c}32.5 \\
1\end{array}$ \\
\hline & $\bar{f}_{n}$ & 7. 86 & 14.0 & 20.8 & 26.0 & 32.0 \\
\hline $\begin{array}{l}\text { A verage of 'normal' } \\
\text { months. }\end{array}$ & $\frac{N}{f_{n}}$ & $\begin{array}{l}393 \\
\quad 7.96\end{array}$ & $\begin{array}{l}260 \\
14.1\end{array}$ & $\begin{array}{l}172 \\
20.2\end{array}$ & $\begin{array}{l}120 \\
26.1\end{array}$ & $\begin{array}{l}59 \\
32.7\end{array}$ \\
\hline
\end{tabular}

The number of recordings obtained during any one month was mainly determined by the weather at the recording site. It was not possible to obtain recordings during periods of rain or gale force winds. This explains the fact that no results were obtained during October 1961, and only a small number of spectra were collected during the winter months November 1961 to January 1962. From the recorded results it would appear that the spectra obtained during July and September 1961 were somewhat anomalous, and these will be discussed later. In the following work these anomalous spectra are excluded from the analysis, only the results obtained during "normal" months being considered.

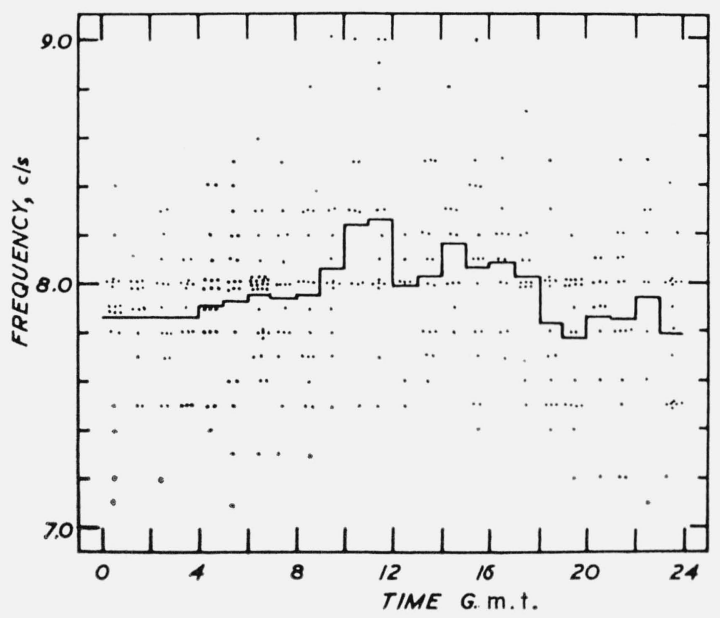

Figure 1. Diurnal variation of first order mode frequency.

(The solid line shows the variation in the hourly mean frequency.)

The greatest weight should be attached to the observations of the first order mode frequency since a large number of these was available. From the data presented in table 1 , there appears to be a slight trend for the mode frequency to fall by 3 percent or so during the recording period. This trend does not appear to the same extent in the results for the higher order mode frequencies.

From the recorded spectra, the diurnal variation of the frequency of the first order mode could be determined. The individual observations of the frequency of this mode are plotted as a function of time of day in figure 1. Examination of the trend of the points appears to indicate a quite definite diurnal variation, there being a maximum around midday and a minimum at midnight. This observation is verified by plotting the diurnal variation of the average frequency in each hourly interval, also shown in figure 1.

The variation in the mean frequency shows two distinct maxima, one centered at 1100 hours U'T with a lesser maximum centered on 1600 hours UT. The total variation is from $7.8 \mathrm{c} / \mathrm{s}$ (midnight) to 8.2 $\mathrm{c} / \mathrm{s}$ at $1100 \mathrm{hr}$.

The individual observations of the frequency of the first order mode are plotted in figure 2 , from which it may be seen that $8 \mathrm{c} / \mathrm{s}$ is by far the most dominant frequency observed.

One observation which was very striking during the processing of the recorded data was the fact that a very marked change in the form of the noise spectrum very often occurred at about 0500 to 0700 hours U'T. An illustration of this phenomenon is given in figure 3.

The reason for this observation is not at all clear, but it is perhaps interesting to note that Gerson [1963] has found that the absorption of HF signals propagating over antipodal paths reaches a maximum at this time. 


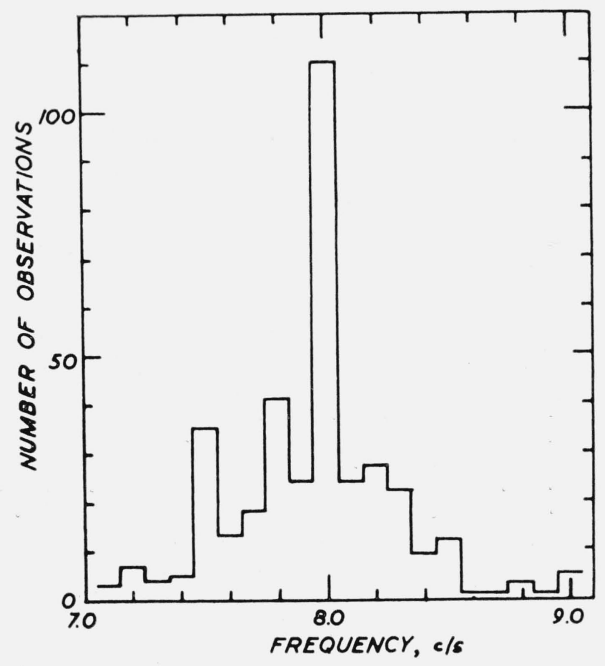

FIGURE 2. Frequency distribution of the observations of the first order model.

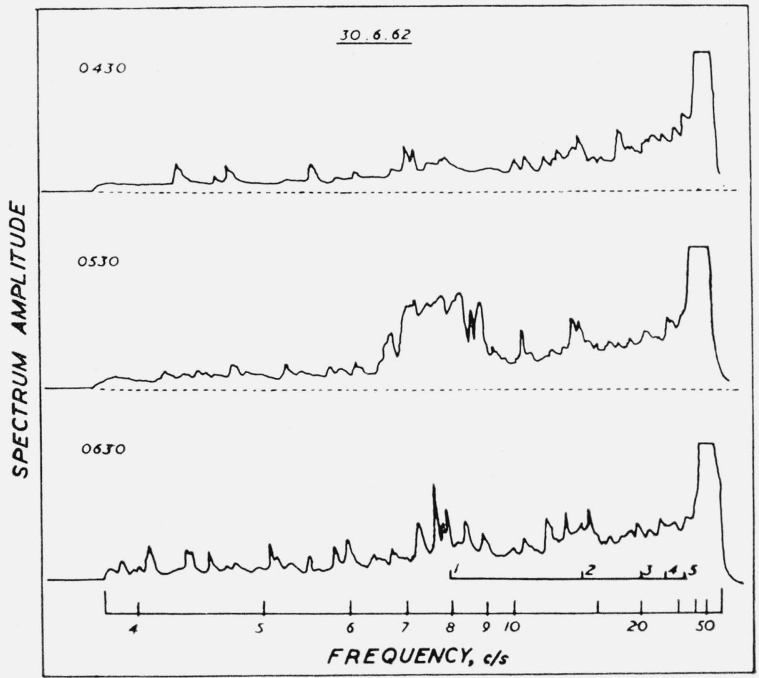

Figure 3. An example of a morning increase in cavity resonance amplitude.

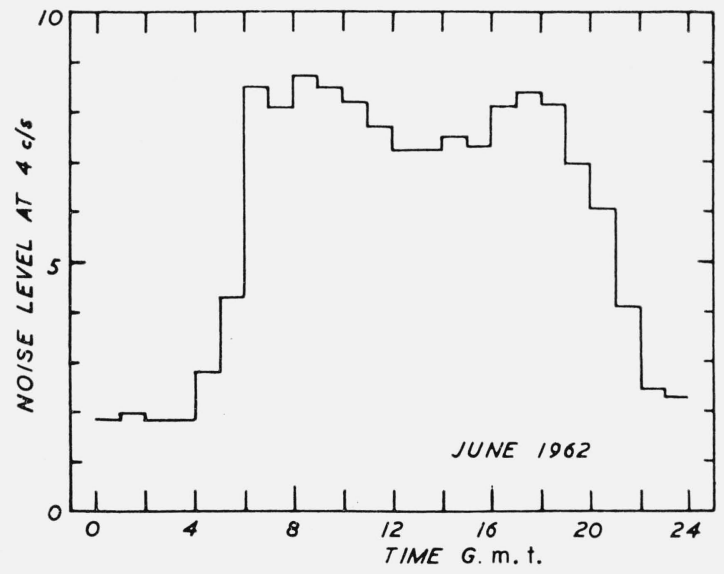

Figure 4. Diurnal variation of the noise level at $4 \mathrm{c} / \mathrm{s}$.
Corresponding to the enhancement of resonator effects at $0600 \mathrm{UT}$, a marked increase in the noise level at $4 \mathrm{c} / \mathrm{s}$ was often observed. The diurnal variation of the noise level for June 1962 has been determined, and the result obtained is illustrated in figure 4.

The diurnal noise level variation is similar to that found for the resonator mode frequency but is rather more marked. It seems likely that the observed variation is largely due to variations in worldwide thunderstorm activity [Balser and Wagner, 1962; Polk and Fitchen, 1964], though the form of the variation is very similar to that of the diurnal changes in long period geomagnetic micropulsation activity.

\subsection{Discussion}

The observed diurnal frequency variation can most probably be ascribed to a variation of $E$ region conductivity on a global basis (see sec. 3). The general form is similar to the local diurnal variations of $f_{0} E$ and MUF predictions for HF communication. This result may be interpreted as being due to a diurnal variation in the mean $E$ region conductivity, possibly due to the fact that at any particular time of year it is winter in one hemisphere (relatively low $E$ region conductivity) and summer in the opposite hemisphere (relatively high $E$ region conductivity).

An interesting phenomenon observed during the recording period is the anomalous observations obtained during July and September 1961. Most of the July results were obtained on the 20th and 21 st, and the September results were obtained on the 7 th, 8th, and 9th. The first order mode frequency was higher than usual, and during July, especially, a marked increase in the amplitudes of the resonances was recorded. During the September period, conditions appeared to be disturbed electrically, and a 'noise storm' was observed on September 8th. July was a very disturbed month magnetically, and it was initially thought that the resonator effects might be connected with geomagnetic activity, though as reported in the literature [Chapman and Jones, 1964a], the frequencies and amplitudes of the modes have been found to show no change during subsequent geomagnetic events of a similar magnitude. A subsequent correlation study between $K_{p}$ and mode frequencies showed that there was no significant connection between these parameters [Jones 1963]. It is now thought that the anomalous spectra could be connected with the occurrence of PCA events. PCA events have been reported as occurring on the 15th and 19th of July and on the 11th and 12th of September [Gillmore, 1963]. As reported by Belrose [1964], such an event is accompanied by a large increase in lower ionosphere conductivity which extends down to latitudes of $60^{\circ}$ at each of the earth's poles. It is considered that while PCA events can bring about marked changes in the properties of the resonator, ordinary magnetic activity has no such effect. 


\section{Theoretical Interpretation of the Experi- mental Observations}

\subsection{Introduction}

Initially, the experimental observations of earthionosphere cavity resonances were interpreted theoretically on the basis of a homogeneous, sharply bounded model ionosphere [Raemer, 1961; Chapman and Jones, 1964a]. Chapman and Jones [1964a] dealt with the derivation of effective ionospheric parameters from the observations of the frequencies of the cavity resonances and showed that the effective conductivity of the ionosphere increased as frequency decreased, this result being attributed to the penetration of the ELF waves into the ionosphere. The same method of interpretation was used by Gendrin and Stefant [1962b] in explaining the observed effects of a high altitude nuclear explosion on the cavity resonances.

From the experimental observations it was possible to determine the variation of the conductivity of the model with frequency and, knowing this variation, the propagation constant of the waveguide formed by the lower ionosphere and the surface of the earth could be deduced [Chapman and Jones, 1964b]. Since the cavity resonances are the result of a worldwide phenomenon, the deduced theoretical results represent an average for worldwide propagation conditions.

The derived values of effective conductivity on the basis of the homogeneous model (approx. $3 \times 10^{-6}$ mhos $/ \mathrm{m}$ ) were much higher than the conductivity actually found in the $D$ region of the ionosphere and were intermediate between $D$ and $E$ region conductivity values obtained by electron density measurements. As had been found earlier by Wait [1958], it was thus apparent that the $E$ region was effective in ELF propagation as well as the $D$ region. As already mentioned, Raemer [1961] had computed the ELF noise spectrum and had shown that the "Q factors" of the resonances predicted on the basis of the homogeneous model wave were too low by a factor of two, thus also illustrating the inadequacy of the homogeneous model.

At these extremely low frequencies it is thus not possible to neglect the effects of the $E$ region on propagation. Galejs [1961b] has calculated the spectrum of ELF noise by approximating closely to ionospheric conductivity profiles using a series of exponential steps. To adopt this procedure in the interpretation of cavity resonances, it is necessary to "average" day and night ionosphere profiles in some way. In order to a void this difficulty, the effects of a two-layer model ionosphere on the cavity resonances has been calculated. It will be seen from what follows that such calculations can provide information on the state of the lower ionosphere and also enable worldwide propagation parameters to be determined.

\subsection{Method of Interpretation on the Basis of a Two-Layer Model}

The basis of the method adopted is the theoretical work of Wait [1958]. It follows from Schumann's [1957] work that the vertical component of the electric field in the earth-ionosphere cavity excited by a lightning discharge can be expressed in the form

$$
E_{r}=A(f) \sum_{n} \frac{f S_{0}^{2}}{f_{n}^{2}-f^{2} S_{0}^{2}}(2 n+1) P_{n}(\cos \theta)
$$

where $n$ represents the order of the resonator mode. $A(f)$ is a term which varies only slowly with frequency compared to the term inside the summation which defines the resonator modes; $S_{0}$ is a factor related to the propagation constant $\Gamma_{0}$ of the fields in the cavity by $\Gamma_{0}=j 2 \pi f S_{0} / c$ and determines the propagation of waves in the zero order waveguide mode [Wait, $1957 \mathrm{a}, \mathrm{b}$ ] $; f_{n}=c \sqrt{n(n+1)} / 2 \pi a$ is the natural (undamped) frequency of the $n$th order resonator mode equal to $10.6,18.3,25.9$, and 33.5 $\mathrm{c} / \mathrm{s}$ for $n=1,2,3$, and 4 .

Schumann had shown that, for a homogeneous ionosphere at low frequencies, $S_{0}$ could be approximately expressed by $S_{0}^{2} \cong 1-m j^{3 / 2} \omega^{-1 / 2}$, where $m$ is an ionospheric loss parameter defined by $m=c / h \sqrt{\omega_{r}}$. If a two-layer model ionosphere is considered (fig. 5) in which the conductivity, $\sigma$, is zero below an altitude $h, \sigma^{\prime}=\epsilon_{0} \omega_{r}^{\prime}$ between altitudes $h$ and $h+s$ and $\sigma^{\prime \prime}=\epsilon_{0} \omega_{r}^{\prime \prime}$ above $h+s$. It then follows from Wait's $[1958,1960]$ work that the parameter $m$ is rendered complex by the stratification and may be expressed in the form

$$
m_{s}=m q
$$

where to a good approximation at the frequencies

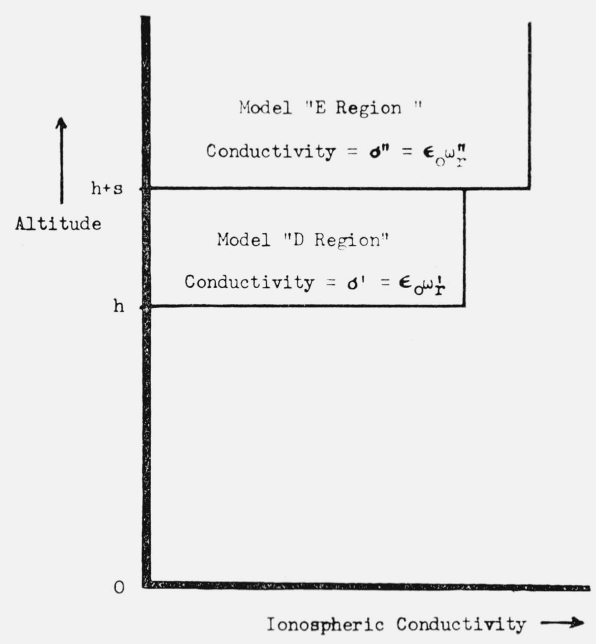

Figure 5. The two layer ionosphere moidel. 
considered here we may write

$$
\begin{aligned}
q & \cong \frac{1+j r \tan k s \mu_{1}}{r+j \tan k s \mu_{1}}=q^{\prime}+j q^{\prime \prime} \\
\mu_{1}^{2} & \cong 1-j \omega_{r}^{\prime} / \omega \text { and } r \simeq \sqrt{\omega_{r}^{\prime \prime} / \omega_{r}^{\prime}}
\end{aligned}
$$

$m$ being the loss parameter appropriate to the lower region $\left(m=c / h \sqrt{\omega_{r}^{\prime}}\right)$.

In the two-layer case, $S_{0}$ may thus be expressed by

$$
S_{0}^{2} \simeq 1-m_{s} j^{3 / 2} \omega^{-1 / 2} .
$$

Subsidiary calculations have shown that (2) is an excellent approximation to the full mode series solutions for $S_{0}$ for frequencies below $40 \mathrm{c} / \mathrm{s}$.

The experimental observations give the frequencies $f_{n}^{\prime}$ at which (1) reaches its maximum values. These maxima are very nearly given by

$$
f_{n}^{2}-f_{n}^{\prime 2} S_{0}^{2}=\text { a minimum. }
$$

Since $S_{0}$ is complex, (3) defines maxima at frequencies given by

$$
\begin{aligned}
\left(f_{n} / f_{n}^{\prime}\right)^{2} & \cong R_{e} S_{0}^{2} \\
& \cong 1+m(2 \omega)^{-1 / 2}\left(q^{\prime}+q^{\prime \prime}\right),
\end{aligned}
$$

where $q=q^{\prime}+j q^{\prime \prime}$. Hence

$$
m\left(q^{\prime}+q^{\prime \prime}\right)=\sqrt{2 \omega_{n}^{\prime}}\left\{\left[f_{n} / f_{n}^{\prime}\right]^{2}-1\right\} .
$$

The right-hand side of (4) may be calculated from the experimental values of $f_{n}^{\prime}$, and thus $m\left(q^{\prime}+q^{\prime \prime}\right)$ can be determined as a function of frequency. The result of this calculation is shown in figure 6 .

In order to compare the derived experimental results with theoretical calculations obtained on the basis of the two-layer model, values of $m\left(q^{\prime}+q^{\prime \prime}\right)$ were calculated for a wide range of the parameters $\omega_{r}^{\prime}, \omega_{r}^{\prime \prime}$, and $s / h$. A suitable range of parameter values was deduced from three sources-from the interpretation of experimental attenuation measurements [Steptoe, 1958], which gives an estimate of $\omega_{r}^{\prime}$ in the range $10^{4}$ to $7 \times 10^{4} \mathrm{sec}^{-1}$; from published ionosphere profiles [Waynick, 1957; Titheridge, 1962]; and from the cavity resonator observations themselves, since at zero frequency $(f=0) m\left(q^{\prime}\right.$ $\left.+q^{\prime \prime}\right)=m / r=c / h \sqrt{\omega_{r}^{\prime \prime}}$. From the experimental curve given in figure 6 , as $f \rightarrow 0, m\left(q^{\prime}+q^{\prime \prime}\right) \rightarrow 5$ or so, thus giving an estimate of $\omega_{r}^{\prime \prime}$ of the order of $10^{6} \mathrm{sec}^{-1}$. It is found that the theoretically deduced variation of $m\left(q^{\prime}+q^{\prime \prime}\right)$ with frequency only matches the experimental curve (fig. 6) for a restricted range of the model parameters. The "best" model has the following parameter values: $\omega_{r}^{\prime}=3 \times 10^{4} \mathrm{sec}^{-1} ; \omega_{r}^{\prime \prime}$ $=1.15 \times 10^{6} \mathrm{sec}^{-1} ; s=30 \mathrm{~km}$, and $h=70 \mathrm{~km}$. Theoretical curves appropriate to this model are shown in figure 6 , where they may be compared with the points derived from the experimental observations. The way in which the model was deduced may be seen from the example given in figure 7 . Similar curves were obtained with $\omega_{r}^{\prime}$ and $s / h$ as abscissa.

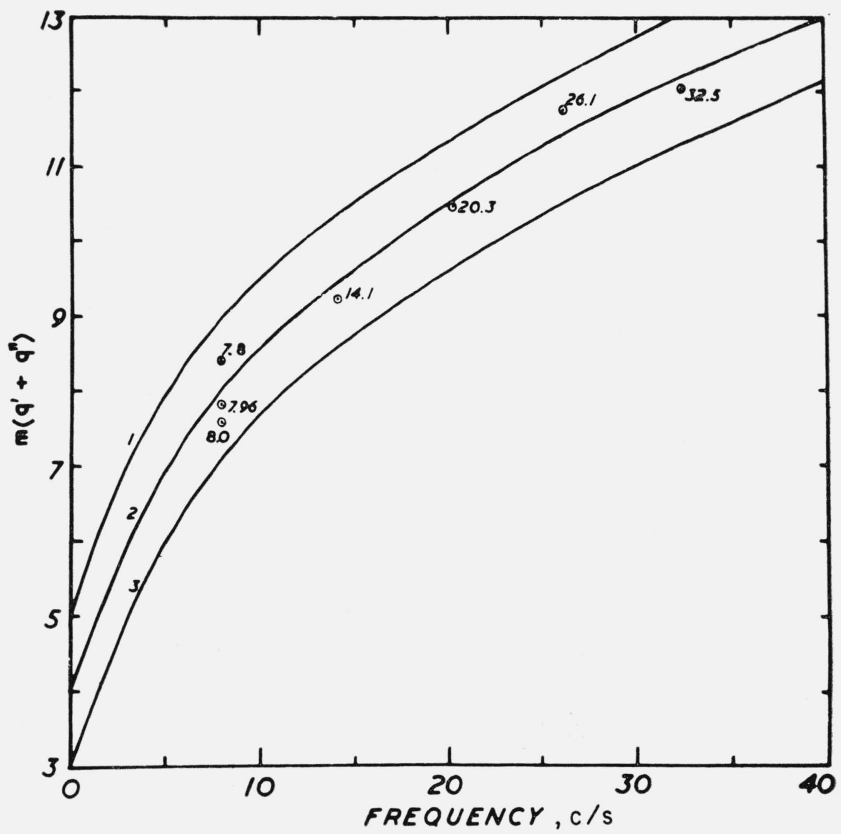

Figure 6. Comparison of values of $\mathrm{m}\left(\mathrm{q}^{\prime}+\mathrm{q}^{\prime \prime}\right)$ derived from the experimental results with theoretical curves.

$\odot$ Points derived from experimental results. (The parameter is resonator mode frequency.)

Theoretical curves for $s / h=30 / 70 ; \omega_{r}^{\prime}=3 \times 10^{4}$, with the following values for $\omega_{\tau}^{\prime \prime}$ :-curve $1,7.35 \times 10^{5}$; curve 2 , $1.15 \times 10^{6}$; curve $3,2.04 \times 10^{6} \mathrm{sec}^{-1}$.

It is found that the value of $\omega_{r}^{\prime \prime}$ is defined quite precisely by the experimental results, while $s / h$ is defined only fairly precisely, and $\omega_{r}^{\prime}$ less precisely. In order to improve the precision with which $\omega_{r}^{\prime}$ could be determined, the predicted attenuation constant of the model was also calculated and compared with the experimental measurements of the attenuation constant of ELF waves of Chapman and Macario [1956] and Jean et al. [1961]. It was concluded that adoption of a value of $3 \times 10^{4} \mathrm{sec}^{-1}$ for $\omega_{r}^{\prime}$ gave attenuation values which fell between the daytime and the nighttime results of Chapman and Macario, as would be expected, and, at the same time predicted, the correct frequencies for the cavity resonances. For daytime propagation a value of $\omega_{r}^{\prime}=5.5 \times 10^{4} \mathrm{sec}^{-1}$ is in excellent agreement with the data of Jean et al. Thus the method of analysis of the experimental data enabled an effective model for ELF to be derived. Having derived a suitable model capable of explaining the frequencies of the cavity resonances and observed values of the attenuation constant, it is possible to deduce the $Q$ factor of the resonances and also the propagation constant appropriate to the model. The calculated value of the $Q$ factor for the first order mode, where "Q factor" is defined in terms of the $3 \mathrm{~dB}$ bandwidth of the resonances, is 4.7. Experimentally, a $Q$ factor of 4.0 may be derived from Balser and Wagner's data [Galejs, 1961a], while for some of the spectra presented by Gendrin and Stefant, a $Q$ factor of 5.3 seems to be appropriate. 


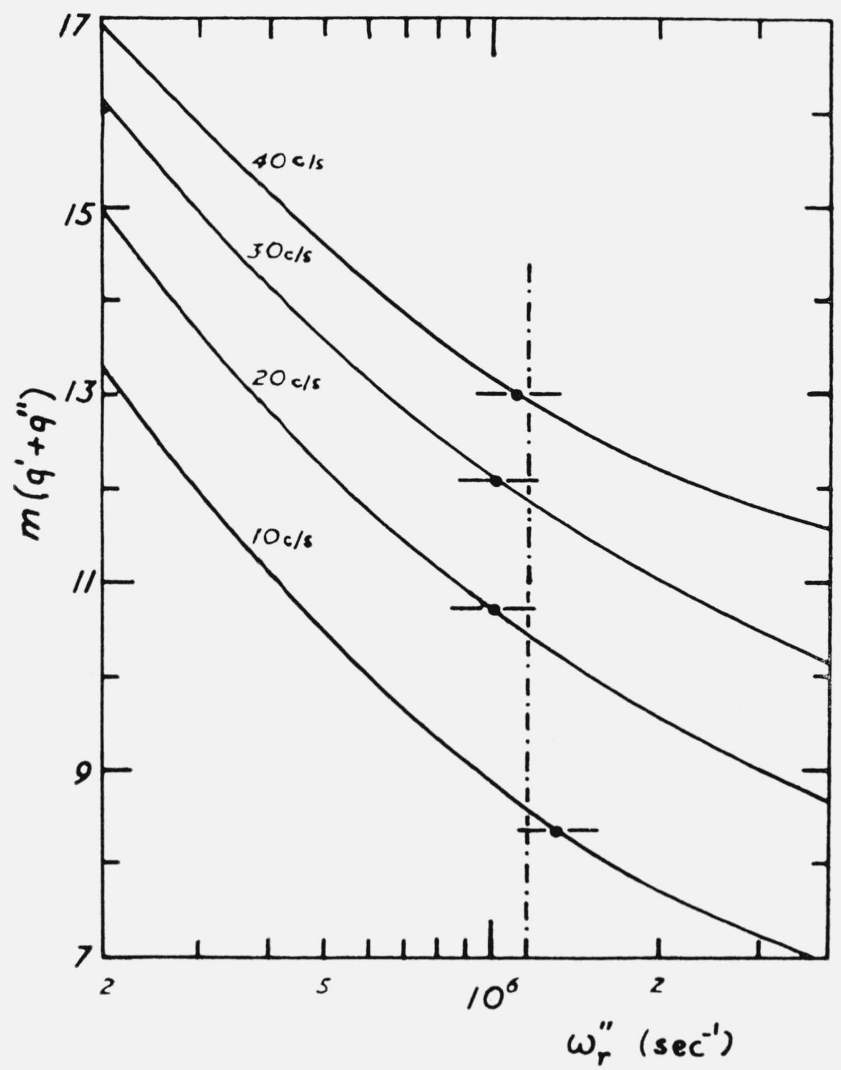

Figure 7. Comparison of the experimentally derived values of $\mathrm{m}\left(\mathrm{q}^{\prime}+\mathrm{q}^{\prime \prime}\right)$ with theory.

Theoretical curves for $s / h=30 / 70$ and $\omega_{r}^{\prime}=3 \times 10^{4} \mathrm{sec}^{-1}$.

Experimental values derived from figure 7 .

'Best' value of $\omega_{r}^{\prime \prime}$

An interpretation of the resonance observed during the PCA conditions of July 1961 and those observed following a nuclear explosion as given by Gendrin and Stefant [1962b] has been made along the lines reported above. The resulting effective models are given in table 2 below.

TABLE 2. Two layer models derived for various conditions

\begin{tabular}{|c|c|c|c|}
\hline & $\omega_{r}^{\prime}\left(\sec ^{-1}\right)$ & $\omega_{r}^{\prime \prime}\left(\sec ^{-1}\right)$ & $s / h$ \\
\hline $\begin{array}{l}\text { Normal model } \\
\text { P.C.A. model-as model } \\
\text { Nuclear explosion mod }\end{array}$ & $\begin{array}{r}3 \times 10^{4} \\
6.8 \times 10^{4} \\
3 \times 10^{4}\end{array}$ & $\begin{array}{r}1.15 \times 10^{6} \\
2.3 \times 10^{7} \\
5 \times 10^{5}\end{array}$ & $\begin{array}{l}30 / 70 \\
37 / 63 \\
30 / 70\end{array}$ \\
\hline
\end{tabular}

The observed effects of the PCA and the nuclear explosion have been discussed previously [Jones, 1963], and the attenuation constant and phase velocity appropriate to these three models has been calculated on the basis of the full mode theory for propagation under a two layer ionosphere by Chapman and Jones [1964b]. Üsing the theory of Wait [1960], the results of this calculation are presented in figure 8 , where they may be compared with the results of Harris and Tanner [1962] and some recent
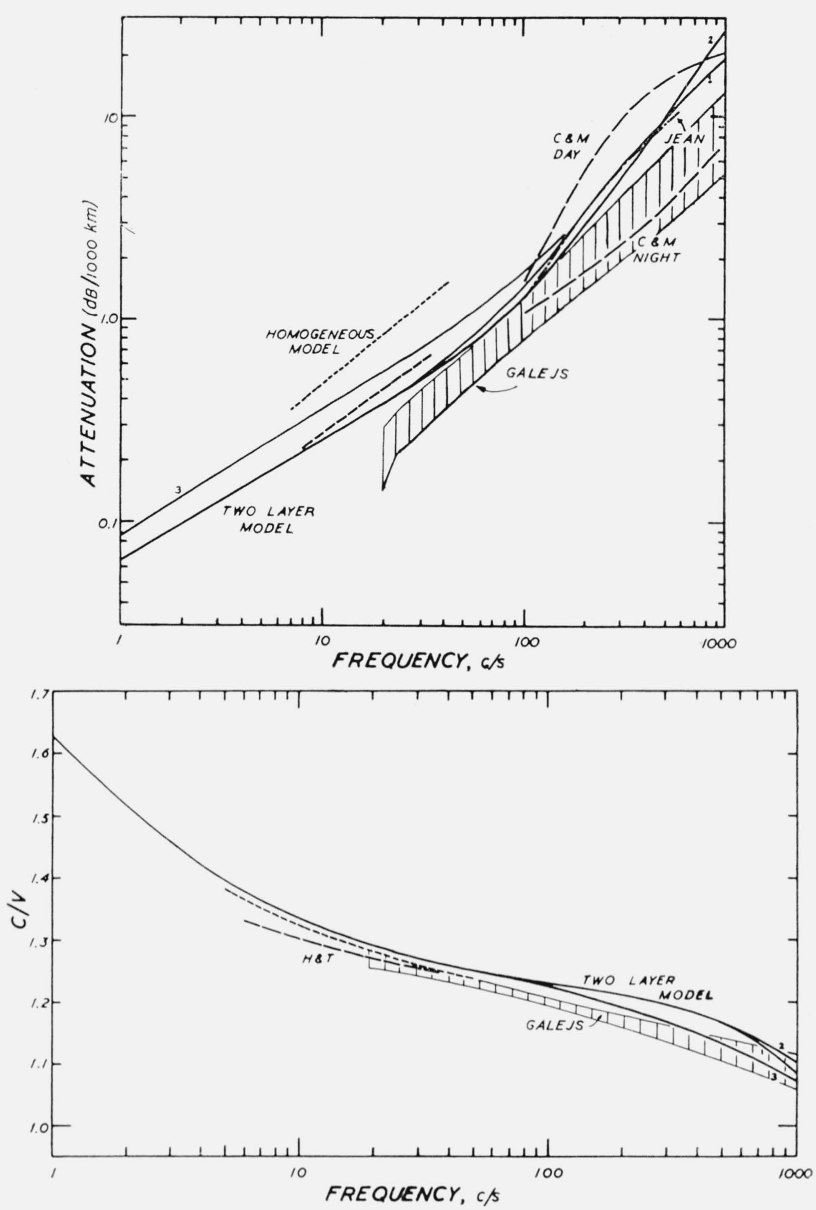

Figures $8 \mathrm{a}$ and $8 \mathrm{~b}$. Derived variation of attenuation and $c / v$ with frequency.

Derived results for two layer models with $s / h=30 / 70$ and $\omega_{r}^{\prime \prime}=1.15 \times 10^{6} \mathrm{sec}^{-1}$.

Derived results for homogeneous model.

Represents the range of values derived by Galejs for different directions of propagation.

Derived results of Harris and Tanner.

Experimental results of Chapman and Macario.

Experimental results of Jean et al. (mean curve)

(For fig. (8a) curve 1 corresponds to $\omega_{r}^{\prime}=5.5 \times 10^{4}$, curve 2 to $\omega_{r}^{\prime}=3 \times 10^{4}$ and curve 3 to the attenuation following the nuclear explosion (see text). In fig. (8b) curve 1 corresponds to $\omega^{\prime}=10^{4}$. curve 2 to $\omega_{r}^{\prime}=3 \times 10^{4}$ and curve 3 to $\omega_{r}^{\prime}=5.5 \times 10^{4}$.).

results of Galejs and Row [1964], the latter having included the effects of the earth's magnetic field. The agreement between the present results and those of the other workers is excellent.

\section{Summary and Discussion}

The frequencies of the resonances excited in the earth-ionosphere cavity by worldwide lightning activity have been observed over a period of 1 year, and the results obtained have been interpreted on the basis of a two-layer model for the ionosphere. In the method employed, the model was varied 
until the correct resonance frequencies were obtained, and it would be expected that this derived model would compare well with the actual profile of the lower ionosphere as determined, for example, by electron density and collisional frequency measurements. A difficulty arises here, however, in that the derived model is an effective model for worldwide propagation, and we should not, therefore, expect any close agreement between the model and profiles obtained at particular localities and times of day. When a comparison is made with daytime profiles, for example that of Titheridge [1962], it can be seen that the thickness and conductivity of the "D region" of the model is a very fair representation of reality, but that the " $E$ region" conductivity is considerably lower than might at first be expected. As mentioned in an earlier publication [Chapman and Jones, 1964b], there are reasons why this should be so. These reasons are connected with the effect of averaging the lower ionosphere profile over the whole earth and with the possible effect of the earth's magnetic field. It should be mentioned that, in connection with the latter, the recent results of Galejs and Row [1964] throw some doubts upon the assumption that at ELF the ionosphere may be regarded as an isotropic medium even in the presence of a magnetic field [Wait, 1960a].

The analysis described above requires a knowledge only of the frequencies of the earth-ionosphere cavity resonances. The model should also, however, explain the $Q$ factors of the resonances. These $Q$ factors have been considered and the calculated values were found to agree well with values derived from experimental observations. A detailed account of these calculations is to be published shortly. It may be noted that if precise values of the $Q$ factors were available it would be possible to determine the propagation constant but only in the cavity resonator region of the spectrum. The approach described above has the advantage of giving the propagation constant over the entire ELF frequency band. In practice the $Q$ factors of the resonances cannot be precisely determined due to background noise problems. Emphasis has thus been placed on the interpretation of the resonance frequencies, and the $Q$ factor of the derived model checked merely to ensure that reasonable values are predicted.

\section{References}

Aarons, J. (1956), Low frequency electromagnetic radiation 10-900 c/s, J. Geophys. Res. 61, No. 4, 647-661.

Aarons, J. (1960a), Correlation of audio frequency electromagnetic radiation with auroral zone micropulsations, Nature 185, 148-151.

Aarons, J. (1960b), Audio frequency electromagnetic radiation in the auroral zone, J. Geophys. Res. 65, 2749-2758.

Balser, M., and C. A. Wagner (1960a), Measurements of the spectrum of radio noise from 50-100 c/s, J. Res. NBS 64D (Radio Prop), No. 4, 415-418.

Balser, M., and C. A. Wagner (1960b), Observations of earthionosphere cavity resonances, Nature, 188, 638-641.

Balser, M., and C. A. Wagner (1962), Diurnal power variations of the earth ionosphere cavity modes, J. Geophys. Res. 6y, 619-625.
Belrose, J. S. (1964), Present knowledge of the lowest ionosphere, Proc. 7th AGARD Ion. Com. Symp. Munich, September 1962, AGARDograph 74. (Pergamon Press, London, England.)

Benoit, R., and A. Houri (1962), Sur la mesure de la densité spectrale d'un bruit en géophysique. Application à la cavité terre-ionosphére, Comptes Rendus 255, 2496-2498.

Chapman, F. W., and D. Llanwyn Jones (1964a), Earthionosphere cavity resonances and effective ionospheric parameters, Proc. 7th AGARD. Ion. Com. Symp. Munich, September 1962, AGARDograph 74. (Pergamon Press, London, England.)

Chapman, F. W., and D. Llanwyn Jones (1964b), Earthionosphere cavity resonances and the propagation of ELF radio-waves, Nature $\mathbf{2 0 2}, 654-657$.

Chapman, F. W., and R. C. V. Macario (1956), Propagation of audio frequency radio waves to great distances, Nature 17\%, 930-933.

Fitzgerald, G. F. (1893), Communication, Nature 48, 526.

Fourier, H. (1960), Quelques aspects des premiers enregistrements magnétotelluriques obtenus a Garchy dans la des variations très rapides, Comptes Rendus 251, 671-673.

Galejs, J. (1961a), ELF waves in the presence of exponential ionospheric conductivity profiles, IRE Trans. Ant. Prop. Ap9, No. 6, 554-562.

Galejs, J. (1961b), Terrestrial ELF noise spectrum in the presence of exponential ionospheric conductivity profiles, J. Geophys. Res. 66, No. 9, 2787-2792.

Galejs, J. (1963), Terrestrial ELF propagation, NATO Advanced Study Institute on Low Frequency Electromagnetic Radiation (Bad Homburg, Germany, July 1963).

Galejs, J., and Ronald V. Row (Jan. 1964), Propagation of ELF waves below an inhomogeneous anisotropic ionosphere, Sylvania Electronics Products Research Report 350R, outline in Radio Sci. J. Res. NBS/USNC-URSI 68D, No. 1, $103-104$.

Gendrin, R., and R. S. Stefant (1962a), Effet de l'explosion thermonucléaire à très haut altitude due 9 juillet 1962 sur la ŕesonance de la cavité terre-ionosphere. i) resultats expérimentaux, Comptes Rendus 255, 752-754.

Gendrin, R., and R. S. Stefant (1962b), Effet de l'explosion thermonucléaire à très haut altitude due 9 juillet 1962 sur la résonance de la cavité terre-ionosphere. ii) interprétation, Comptes Rendus 255, 2273-2275.

Gerson, N. C. (1963), Very long distance propagation, J. Atmospheric Terrest. Phys. 25, 451-465.

Gillmor, C. S. (1963), The day-to-night ratio of cosmic noise absorption during PCA events, J. Atmospheric Terrest. Phys. 25, 263-266.

Gorskii, S. M., and V. A. Krotov (1961), Some characteristics of atmospheric noise in the band $2-25 \mathrm{c} / \mathrm{s}$, Izvestia V.U.Z. (Radiophysics) 4, No. 6, 1025-1027.

Haraldson, S. (1961), Rapid geomagnetic fluctuations, Tellus 13, No. 3, 432-437.

Harris, F. B., and R. L. Tanner (1962), A method for the determination of lower ionosphere properties by means of field measurements on sferics, J. Res. NBS 66D (Radio Prop.), No. 4, 463-478.

Jean, A. G., A. C. Murphy, J. R. Wait, and D. F. Wasmundt (1961), Observed attenuation rates of ELF radio waves, J. Res. NBS 65D (Radio Prop.), No. 5, 475-479.

Jones, D. Llanwyn (1963), Observations of ELF electromagnetic noise of terrestrial origin, Univ. London $\mathrm{Ph}$. D. Thesis, Sept. 1963.

König, H. (1954), Observation of atmospherics with very low frequencies, Naturwissenschaften 41, No. 8, 183-184.

König, H. (1959), Atomospherics geringster frequenzen, Z. Angew. Phys. 11, No. 7, 264-274.

Large, M. I., and T. W. Wormell (1958), Fluctuations in the vertical electric field in the frequency range from $1 \mathrm{c} / \mathrm{s}$ to $500 \mathrm{c} / \mathrm{s}$, Advances in Atmospheric Electricity, p. 603-607. (Pergamon Press, London, England).

Lokken, J. E., et al. (1961), Stanford-Pacific Naval laboratory conjugate Point experiment, Nature 192, 319-329.

Madden, T. R., et al. (1962), Progress report on geomagnetic studies and conductivity in the earth's crust, M.I.T. (USA) Report, Project NR-371-401. 
Polk, C., and F. Fitchen (1962), Schumann resonances of the earth ionosphere cavity-ELF reception at Kingston, R.I., J. Res. NBS 66D (Radio Prop.), No. 3, 313-318.

Polk, C., and F. Fitchen (1964), ELF propagation and the earth-ionosphere resonant cavity, Proc. 7th AGARD Ion. Com. Symp. Munich, September 1962, AGARDograph 74. (Pergamon Press, London, England).

Raemer H. (1961), On the spectrum of terrestrial radio noise at ELF, J. Res. NBS 65D (Radio Prop.), No. 6, 581-593.

Ryecroft, M., and Wormell (1964), The natural ELF electromagnetic noise in the band $2-40 \mathrm{c} / \mathrm{s}$, Proc. 7th AGARD Ion. Com. Symp. Munjch, September 1962, AGARDograph 74. (Pergamon Press, London, England).

Schumann, W. O. (1952a), Über die strahlungslosen Eigenschwingungen einer leitenden Kugel, Die von einer Luftschicht und einer ionosphärenhulle umgeben ist, Z. Naturforschg 7a, $149-154$.

Schumann, W. O. (1952b), Über die dämpgung der elektromagnetischen Eigenschwingungen des svstems Erde-Luftionosphäre, Z. Naturforschg 7a, 250-252.

Schumann, W. O. (1957), Über elektrische Eigenschwingungen des Hohlraumes Erde-Luft-Ionosphäre erregt durch Blitzentladungen, Z. Angew. Phys. 9, No. 8, 373-378.

Steptoe, B. J. (1958), The spectrum and propagation of atmospheries, Univ. London Ph. D. Thesis.
Stefant, R. (1960), Détection de l'activité du champ magnétique'terrestre dans la band $5-50 \mathrm{~Hz}$, Comptes Rendus 251, $857-859$

Titheridge, J. E. (1962), The electron density in the lower ionosphere, J. Atmospheric Terrest. Phys. 24, 269-282.

Wait, J. R. (1957a), The mode theory of VLF ionospheric propagation for finite ground conductivity, Proc. IRE 45, $760-765$

Wait, J. R. (1957b), The attenuation vs. frequency characteristics of VLF radio waves, Proc. IRE 45, 786-771.

Wait, J. R. (1958), An extension to the mode theory of VLF ionospheric propagation, J. Geophys. Res. 63, No. 1, 125135.

Wait, J. R. (1960a), Mode theory and the propagation of ELF radio waves, J. Res. NBS 64D (Radio Prop.), No. 4, $387-404$.

Wait, J. R. (1960b), Terrestrial propagation of VLF radio waves, J. Res. NBS 64D (Radio Prop.), No. 2, 153-203.

Waynick, A. H. (1957), The present state of knowledge concerning the lower ionosphere, Proc. IRE 45, 741-749.

(Paper 68D11-418) 